\title{
Bone Quality in CKD Patients: Current Concepts and Future Directions - Part I
}

\author{
Kamyar Asadipooya ${ }^{\mathrm{a}}$ Mohamed Abdalbary $^{\mathrm{b}, \mathrm{c}}$ Yahya Ahmad $^{\mathrm{b}}$ Elijah Kakani ${ }^{\mathrm{b}}$ \\ Marie-Claude Monier-Faugere ${ }^{b}$ Amr El-Husseini ${ }^{b}$

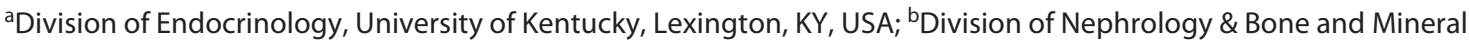 \\ Metabolism, University of Kentucky, Lexington, KY, USA; 'Nephrology and Dialysis Unit, Mansoura University, \\ Mansoura, Egypt
}

\section{Keywords \\ Chronic kidney disease $\cdot$ Bone quality $\cdot$ Bone mineral density}

\begin{abstract}
Background: There is ample evidence that patients with CKD have an increased risk of osteoporotic fractures. Bone fragility is not only influenced by low bone volume and mass but also by poor microarchitecture and tissue quality. More emphasis has been given to the quantitative rather than qualitative assessment of bone health, both in general population and CKD patients. Although bone mineral density (BMD) is a very useful clinical tool in assessing bone strength, it may underestimate the fracture risk in CKD patients. Serum and urinary bone biomarkers have been found to be reflective of bone activities and predictive of fractures independently of BMD in CKD patients. Bone quality and fracture risk in CKD patients can be better assessed by utilizing new technologies such as trabecular bone score and high-resolution imaging studies. Additionally, invasive assessments such as bone histology and micro-indentation are useful counterparts in the evaluation of bone quality. Summary: A precise diagnosis of the underlying skeletal abnormalities in CKD patients is crucial to prevent further bone loss and fractures. We
\end{abstract}

must consider bone quantity and quality abnormalities for management of CKD patients. Here in this part I, we are focusing on advances in bone quality diagnostics that are expected to help in proper understanding of the bone health in CKD patients. Key Messages: Assessment of bone quality and quantity in CKD patients is essential. Both noninvasive and invasive techniques for the assessment of bone quality are available.

(C) 2021 The Author(s)

Published by S. Karger AG, Basel

\section{Introduction}

CKD affects $8-10 \%$ of the population [1]. The fracture risk in $\mathrm{CKD}$ patients increases with worsening kidney function, suggesting specific CKD-related causes. Bone disease is a major complication of CKD and is a manifestation of CKD-mineral bone disorder. Renal osteodystrophy (ROD) is an alteration of bone morphology in patients with CKD and is a measure of the skeletal compo-

Part II: Asadipooya et al.: "Bone Quality in CKD Patients: Current Concepts and Future Directions - Part II." Kidney Dis. DOI: $10.1159 / 000515542$.

karger@karger.com www.karger.com/kdd

Karger $\stackrel{\text { ' }}{5}$

BOPEN ACCESS
(C) 2021 The Author(s)

Published by S. Karger AG, Basel

This is an Open Access article licensed under the Creative Commons Attribution-NonCommercial-4.0 International License (CC BY-NC) (http://www.karger.com/Services/OpenAccessLicense), applicable to the online version of the article only. Usage and distribution for commercial purposes requires written permission.
Correspondence to:

Amr El-Husseini, amr.elhusseini.moh@uky.edu 


\begin{tabular}{|c|c|c|c|}
\hline & & PROS & CONS \\
\hline $\begin{array}{l}\text { PTH \& bone } \\
\text { turnover markers }\end{array}$ & & $\begin{array}{l}\text { - Noninvasive } \\
\text { - Aids in prediction of bone turnover }\end{array}$ & - Because of renal clearance, osteocalcin, P1NP and CTX has limited use in CKD \\
\hline BMD- DEXA & & $\begin{array}{l}\text { - Widely available and noninvasive } \\
\text { - Low radiation exposure } \& \text { used in FRAX } \\
\text { - Correlates with cortical porosity in CKD }\end{array}$ & $\begin{array}{l}\text { - Unable to assess type of ROD } \\
\text { - Assess areal density only } \\
\text { - Cannot distinguish cortical from trabecular bone }\end{array}$ \\
\hline $\begin{array}{l}\text { Trabecular bone } \\
\text { score }\end{array}$ & & $\begin{array}{l}\text { - Noninvasive, Independent fracture predictor } \\
\text { - Can be applied retrospectively to DEXA } \\
\text { No extra radiation, time and expense }\end{array}$ & $\begin{array}{l}\text { - Cannot detect type of ROD } \\
\text { - Image noise degrades resolution } \\
\text { - Variability among various software's }\end{array}$ \\
\hline $\begin{array}{l}\text { Quantitative } \\
\text { ultrasound }\end{array}$ & & $\begin{array}{l}\text { - Non invasive with no radiation exposure } \\
\text { - Portable } \\
\text { - Correlates with BMD-DEXA }\end{array}$ & $\begin{array}{l}\text { - Only at distal extremity sites } \\
\text { - Inter-observer variability } \\
\text { - Lack of fracture predictability data in CKD }\end{array}$ \\
\hline QCT & & $\begin{array}{l}\text { 3D volumetric assessment of spine and femur } \\
\text { - Not affected by extra skeletal calcification }\end{array}$ & $\begin{array}{l}\text { - High radiation exposure } \\
\text { - Expensive and cannot detect type of ROD }\end{array}$ \\
\hline HRpQCT & & $\begin{array}{l}\text { - Assesses microarchitecture noninvasively } \\
\text { - Good cortical and trabecular differentiation } \\
\text { Correlates with bone histopathology }\end{array}$ & $\begin{array}{l}\text { - Expensive and not widely available } \\
\text { - Investigational tool only } \\
\text { Only distal extremity site (tibia and radius) }\end{array}$ \\
\hline HR-MRI & & $\begin{array}{l}\text { - Non-ionizing } \\
\text { Can image central bones (hip) }\end{array}$ & $\begin{array}{l}\text { - Expensive } \\
\text { - Not widely available }\end{array}$ \\
\hline $\begin{array}{l}\text { Finite element } \\
\text { analysis (FEA) }\end{array}$ & & $\begin{array}{l}\text { - Improves bone quality assessment by } \mathrm{CT} \text { and } \mathrm{MRI} \\
\text { - Aids } \mathrm{CT} \text { and } \mathrm{MRI} \text { in evaluating mechanical properties } \& \text { fracture prediction }\end{array}$ & $\begin{array}{l}\text { - Lack of standardization } \\
\text { - Various loading conditions can affect the estimation of strength }\end{array}$ \\
\hline $\begin{array}{l}\text { Reference point } \\
\text { indentation }\end{array}$ & & $\begin{array}{l}\text { - Good in-vivo measure of bone stiffness \& quality } \\
\text { - Correlates well with fracture risk } \\
\text { Correlates with BMD and TBS in CKD }\end{array}$ & $\begin{array}{l}\text { - Invasive and can cause local complications } \\
\text { - Does not represent whole bone strength } \\
\text { Does not detect type of ROD }\end{array}$ \\
\hline Bone biopsy & & $\begin{array}{l}\text { - Gold standard as it directly assesses bone turnover, mineralization and } \\
\text { volume } \\
\text { - Assess bone marrow, can detect heavy metals and micro-cracks }\end{array}$ & $\begin{array}{l}\text { - Invasive and cannot detect whole bone strength } \\
\text { - Not widely available and needs expertise }\end{array}$ \\
\hline $\begin{array}{l}\text { FTIR \& } \\
\text { nano-indentation }\end{array}$ & & $\begin{array}{l}\text { - Provides data on bone material properties } \\
\text { - Adds additional information about bone quality }\end{array}$ & $\begin{array}{l}\text { - Limited availability and needs bone tissue } \\
\text { - Only provides relative measures of mineral/matrix etc }\end{array}$ \\
\hline
\end{tabular}

Fig. 1. The pros and cons of each method of bone quality assessment in CKD patients.

nent of the systemic disorder of CKD-mineral bone disorder, which is quantifiable by histomorphometry [2].

Because of the ease of use and widespread availability of dual-energy X-ray absorptiometry (DEXA), operationally the World Health Organization (WHO) defined osteoporosis as a reduction in bone mineral density (BMD) $t$ scores of $\geq 2.5$ standard deviations from the mean value in young adults [3]. This definition is now routinely used worldwide in clinical practice for the diagnosis of osteoporosis. Fractures may also occur, however, with low-energy trauma in non-osteoporotic patients, as classified based on their BMD $t$ scores [4-6]. In 2000, the NIH defined osteoporosis as "a skeletal disorder characterized by compromised bone strength predisposing to an increased risk of fracture." Bone strength reflects the integration of 2 main components: bone quantity and bone quality [7].

Thus, bone quantity (assessed by DEXA to give 2-dimensional areal BMD or with quantified 3-dimensional quantitative computed tomography [QCT] for volume) is only one component. Bone quality is a second major component and includes bone remodeling abnormalities, collagen cross-linking, and mineralization properties.
Remodeling abnormalities are generally evaluated with bone biopsy and dynamic histomorphometry (tetracycline labeling), and such abnormalities are nearly universal in patients with CKD [8].

WHO developed a Fracture Risk Assessment Tool (FRAX) in the general population [9]. The addition of BMD to the FRAX score improves the prediction of fracture risk; however, bone quality is not included in this tool. There is an option to say yes or no to secondary osteoporosis; however, this does not include CKD. It might be useful to add bone quality measurement in the general population and the CKD as a secondary cause of osteoporosis to improve fracture risk prediction.

Bone quality can be evaluated by studying bone volume, microarchitecture, material properties, and microdamage. All these factors can be assessed at macro, micro, and nano hierarchical levels by various diagnostic modalities [10]. Of the spectrum of methods available to assess bone quality from several different perspectives, we describe the clinically relevant ones. The pros and cons of each method of bone quality assessment in CKD patients are included in Figure 1. 


\section{PTH and Bone Turnover Markers}

Bone turnover markers (BTMs) give an idea of the bone resorption and bone formation rate. They provide an integrated dynamic assessment of skeletal metabolism and facilitate ROD management [11]. Bone formation markers including bone-specific alkaline phosphatase (BSAP), osteocalcin, and procollagen type-1 N-terminal propeptide (P1NP) are markers of osteoblast function. Bone resorption markers such as tartrate-resistant acid phosphatase $5 b$ (Trap-5b) and C-terminal telopeptides of type I collagen (CTX) are markers of osteoclast function. BSAP and Trap-5b are not cleared by the kidneys, hence used in CKD patients. On the other hand, osteocalcin, P1NP monomer, and CTX are cleared by the kidneys, and their usefulness in CKD patients remains unclear. Serum intact PTH (iPTH) and BSAP are the most commonly used turnover markers to discriminate renal bone disease. In dialysis patients, Sprague et al. [12] reported that iPTH and whole PTH (wPTH) level of $<2$ times the upper limit of normal had a sensitivity of 65 and $74 \%$ and a specificity of 67 and 57\%, respectively, for low-turnover bone disease (LTBD). iPTH and $\mathrm{wPTH}_{\mathrm{P}} \mathrm{Pf}>9$ times the upper limit of normal showed a sensitivity of 37 and $31 \%$ and a specificity of 86 and $88 \%$, respectively, for high-turnover bone disease (HTBD) [12]. Monier-Faugere et al. [13] studied PTH-(1-84)/-(7-84) ratio. They found that a ratio of $>1$ had $100 \%$ sensitivity for HTBD, and a ratio of $<1$ had $100 \%$ sensitivity for LTBD. Ureña et al. [14] demonstrated that BSAP $>20$ and $<20 \mathrm{ng} / \mathrm{mL}$ has $100 \%$ sensitivity and specificity for HTBD and LTBD, respectively, in hemodialysis (HD) patients.

BTMs also assist in bone loss and fracture risk prediction in CKD patients. In a cross-sectional study, Nickolas et al. reported that osteocalcin, P1NP, and Trap-5b discriminated fracture status in pre-dialysis CKD patients independent of BMD. They also noted a strong relationship between $\mathrm{iPTH}$ and BTMs, trabecular volumetric $\mathrm{BMD}$, and microarchitecture compared to cortical volumetric BMD or thickness. They explained this by the effect of hyperparathyroidism preferentially on the metabolically active trabecular bone [15]. However, the same group, in a more recent longitudinal study of CKD patients (including dialysis), showed that hyperparathyroidism and high BTMs were associated with decreased cortical density and thickness but not with trabecular changes [16].

Laowalert et al. [17] in a recent study found that serum iPTH $>484.5$ or TRAP- $5 \mathrm{~b}>1.9 \mathrm{pg} / \mathrm{mL}$ has $92 \%$ sensitivity and $50 \%$ specificity for prediction of HTBD in Asian HD patients. The sensitivity goes down to $58 \%$ but the specificity goes up to $100 \%$ when they combined both. Limori et al. [18] found that iPTH levels of $<150$ or $>300 \mathrm{pg} / \mathrm{mL}$ along with higher BSAP levels $(>19.9 \mu \mathrm{g} / \mathrm{L})$ were associated with a higher fracture risk in ESRD. Perrin et al. [19] reported that iPTH levels $\geq 130 \mathrm{pg} / \mathrm{mL}$ at 3 months posttransplantation predicted incident fractures in kidney transplant recipients.

In our laboratory, we previously studied FGF23 as a potential bone marker in adult dialysis patients. FGF23 correlated well with mineralization parameters. Patients with very high FGF23 levels had normal mineralization lag time [20]. Activin A is considered a regulator of bone turnover and is one of the markers of increased osteoclast activity [21]. Our group previously reported that serum activin $\mathrm{A}$ is one of the first biomarkers that goes up in ROD and correlates well with bone turnover [22].

Sclerostin levels increase with CKD progression, and its serum levels are associated with cardiovascular events $[23,24]$. Osteocytes are the main source of sclerostin, though kidney, liver, and vascular wall can secrete it too [25]. Mare et al. [26] reported a negative correlation between skeletal and circulating sclerostin levels with histomorphometric measures of bone turnover. Cejka et al. [27] previously described a promising role of serum sclerostin level in addition to iPTH in the diagnosis of HTBD in dialysis patients. Furthermore, Malluche et al. [28] found that baseline serum sclerostin and Trap-5b levels predicted bone loss. Circulating sclerostin is dialyzable, so timing of blood draw is crucial while interpreting the results in dialysis patients [29]. Furthermore, in patients undergoing peritoneal dialysis, sclerostin is present in very high concentrations in the peritoneal fluid [30]. Thus, the utility of serum sclerostin as a BTM in CKD, especially in $\mathrm{HD}$ and peritoneal dialysis patients, is yet to be determined.

\section{DEXA Scans: BMD and Trabecular Bone Score}

It is challenging to diagnose osteopenia based on plain radiographs. Conventional X-ray films are insensitive to the changes in BMD. Patient might lose up to $50 \%$ of bone mass before it can be detected on a lumbar radiography [31]. Moreover, it is a subjective rather than objective tool with a significant interobserver variabilities. The agreement between the readers for the diagnosis of osteopenia based on X-ray was achieved only in $43 \%$ of all radiographs [32]. 
Although it is widely available and a good test for bone quantity, DEXA areal BMD does not detect the type of ROD in CKD patients and cannot evaluate bone quality. Other limitations of DEXA scans include the confounding effects of surrounding soft tissue, bone artifacts caused by osteoarthritis, degenerated disks, vertebral compression fractures, and aortic calcification, which are not uncommon in CKD patients. However, femoral BMD is correlated with cortical porosity histomorphologically in dialysis patients [33]. Because DEXA is a 2-dimensional technique, it also cannot be used to measure true volumetric BMD (vBMD) and bone size or to separate trabecular from cortical bone. Thus, a large bone will yield a higher areal BMD than a small bone, although the $\mathrm{BMD}$ would be the same.

Fractures occur in $30-50 \%$ of people with normal $\mathrm{BMD}$. This might be due to lack of capturing of poor bone quality by DEXA scans. Trabecular bone score (TBS) captures vertebral trabecular texture from the lumbar DEXA images [34]. It is a noninvasive tool to assess bone microarchitecture. TBS does not add any extra time, cost, or radiation exposure to the DEXA scans. The TBS software can be applied retrospectively to BMD images to better assess the bone quality and thus the fracture risk. TBS software has been modified over the past few years. TBSv1 algorithm was the initial software utilized to assess bone quality, which was developed after studies on females with average body habitus. The reference values could not correlate well in male population or people with a BMI of $<15$ or $>35$. TBS-v2 algorithm was developed to counter the shortcomings of the previous TBS version, and it has improved the fracture prediction [35].

Certain conditions like CKD, diabetes, obesity, and long-term glucocorticoid use have increased fracture risk despite normal BMD. All these conditions affect bone quality, particularly trabecular microarchitecture. TBS can be extremely helpful in predicting fracture risk and assessment of bone quality in these circumstances [3638]. TBS is usually low in patients with CKD including dialysis patients [39]. TBS correlated better with incidence of fracture in pre-dialysis CKD, dialysis patients, and kidney transplant recipients, as compared to BMD $[40,41]$. In a multivariate analysis in ESRD patients by Ramalho et al. [42], TBS was correlated with trabecular bone volume and trabecular width histopathologically. However, Holloway-Kew et al. [43] found that TBS and $\mathrm{BMD}$ did not correlate with prior history of fractures in CKD patients compared to micro-indentation parameters.
Perez-Saez et al. [44] reported that despite a persistent decline in the BMD, TBS and bone quality stayed normal up to 10 years after kidney transplantation. Furthermore, Silva et al. [40] previously reported that TBS can be used as a tool to assess the response to different therapeutic interventions. They demonstrated a maximal TBS improvement with teriparatide followed by denosumab and tamoxifen, then bisphosphonates in older women.

\section{Quantitative Ultrasound}

Quantitative ultrasound (QUS) machines employ waves with lower frequencies compared to the conventional soft tissue US. The studied skeletal sites are the distal metaphysis of the phalanx, the calcaneus, the radius, and the tibia. All these sites are predominantly cortical bone, except the calcaneus, which is mainly composed of trabecular bone [45].

As QUS waves propagate through the bone, their velocity reflects the material properties of the bone such as its density, architecture, and elasticity. The degree of attenuation of the wave amplitude, measured by broadband ultrasound attenuation, is influenced by trabecular separation and other structural characteristics of trabecular bone. Several other more complex wave parameters such as shape (number of peaks), bone transmission time, and amplitude-dependent speed of sound (SOS) have been developed, and these have been correlated with several bone properties measured by micro-CT [46].

In the 1990s, studies on QUS showed that SOS measured in bones such as tibia inversely correlated with dialysis vintage and iPTH levels [47]. Similarly, in a study employing phalangeal QUS in HD patients, amplitudedependent SOS was significantly lower compared to control groups, and it was negatively correlated with iPTH levels [48]. Furthermore, HD patients had reduced calcaneal broadband ultrasound attenuation and SOS scores compared to controls, and there was a significant association between calcaneal QUS parameters and DEXA scans [49]. QUS measures have been correlated with DEXA at both phalanges and calcaneus $[50,51]$. In osteoporotic patients, QUS measurements have been used to monitor the effects of treatment with alendronate, raloxifene, and teriparatide [45]. Ten-year fracture risk probabilities have been calculated using QUS measures in osteoporotic patients [52]. However, the predictive value for CKD patients has not been studied, and it is an interesting potential topic for future research. It might also have an application in monitoring of therapy in ROD. 


\section{Quantitative Computed Tomography}

QCT is an in vivo diagnostic modality that can be applied to the axial or appendicular skeleton, where large body segments such as hip or spine are imaged to measure vBMD. One of the main advantages of QCT, particularly in CKD patients, is that it is not confounded by the presence of extra-osseous calcium, which can be a problem with DEXA scans. It also better identifies bone loss over time compared to DEXA in HD patients [53]. The disadvantages of this method include high radiation exposure and cost and it does not assess the type of ROD.

\section{High-Resolution Peripheral Quantitative Computed Tomography}

High-resolution peripheral quantitative computed tomography (HRpQCT) is another tool that employs narrower slice width and field of view compared to QCT and maximizes spatial resolution using image reconstruction algorithms. It is a good tool to assess bone microarchitecture (cortical porosity and trabecular connectivity) and vBMD at distal extremity sites such as distal radius and tibia. It provides more detailed information about bone microstructure than QCT, which does not detect trabecular thickness or cortical porosity [10]. Measurement of bone microarchitecture by HRpQCT in addition to $\mathrm{BMD}$ can explain the variance in bone strength. Studies using HRpQCT have demonstrated a preferential loss of cortical bone in CKD patients [16]. In CKD stages 2-4, before the onset of secondary hyperparathyroidism (SHPT), impairment of trabecular bone is noted with HRpQCT, and this could explain the increased risk of fractures in early CKD. As CKD progresses and SHPT ensues, with increased turnover, bone loss assessed by HRpQCT is predominantly cortical and is highly associated with fractures in weight-bearing and non-weight-bearing sites [16, 54]. Measures of bone microarchitecture obtained by HRpQCT have been validated against bone micro-CT [55]. Nickolas et al. [15] in a cross-sectional study in pre-dialysis patients demonstrated that several HRpQCT measures of microarchitecture were significantly lower in patients with fractures. In CKD patients with HTBD and osteoporosis, there is cancellization of endocortical bone. This cancellization can confound cortical measurements obtained by HRpQCT and can lead to errors in quantifying changes in trabecular and cortical morphology [56].

\section{High-Resolution Magnetic Resonance Imaging or Micro-Magnetic Resonance Imaging}

High-resolution magnetic resonance imaging (HRMRI) or micro-MRI is a noninvasive and nonionizing method for the quantification of bone microarchitecture. Whereas HRpQCT is limited to places like ankle and wrist, HR-MRI can measure other sites like the proximal femur. In a small cross-sectional study in patients with ROD, MRI indices of trabecular network integrity correlated with histomorphometric trabecular bone volume, separation, and thickness. HR-MRI parameters also correlated with trabecular separation measured by micro-CT and turnover indices [57]. Parameters of bone microarchitecture obtained by both HR-MRI and HRpQCT have been correlated with bone strength using finite element analysis (FEA) [58, 59].

\section{Finite Element Analysis}

FEA is a computational method that provides information on bone quality, microarchitecture, fracture risk, and mechanical properties. It can be generated through QCT, HRpQCT, or MRI data. CT-based FEA improved assessment of bone strength compared to DXA or QCT but is not standardized, and variability in loading conditions can affect the strength estimates [60,61]. MRI-based FEA improved diagnosis precision, predicted fracture, and was useful for monitoring bone loss and response to treatment [61]. HRpQCT-based FEA cortical thickness and volume correlated with BTMs, while cortical porosity correlated with PTH in a cross-sectional study in ESRD patients [62]. MRI-based micro-FEA mechanical parameters significantly decreased 6 months after kidney transplantation, but structural parameters did not change significantly by using micro-MRI only [59].

\section{Reference Point Indentation}

Reference point indentation (RPI) is a less invasive measure of bone material strength (BMS) compared to bone biopsy. The RPI instrument performs bone indentation testing by inserting a probe assembly through skin and subcutaneous tissues directly onto the surface of the bone after displacing the overlying periosteum in a very small area. Microscopic fractures are then induced on the surface of the bone, and bone mechanical properties at tissue level are measured. Local infection and edema may 
preclude the use of these methods. People on anticoagulants need special attention to hemostasis [63]. Osteoprobe is a newer version of RPI that measures bone material properties by evaluating the BMS index without displacing the periosteum or using a reference probe [64, 65]. Patients with atypical femoral fractures have significant abnormalities in BMS measurements using the RPI methods despite having normal DEXA-BMD scores [66].

\section{Bone Biopsy and Histopathology}

Bone biopsies are performed at the anterior iliac crest after double tetracycline labeling [67]. For diagnostic purposes, pathologists perform a qualitative comprehensive assessment of the bone specimens $[67,68]$. In addition, for research purposes, quantitative histomorphometric analysis of bone sections may be used. Furthermore, bone quality and mechanical properties can be evaluated using various methods such as Fourier transform infrared (FTIR) spectroscopy, FEA, and nano-, micro- and macro-indentation [69, 70].

In 2006, the Kidney Disease: Improving Global Outcomes (KDIGO) introduced the notion that bone histological abnormalities in patients with CKD should be characterized by bone turnover, mineralization, and volume [71]. Bone turnover is classified as low, normal, or high. Mineralization is characterized as normal or abnormal, and volume as low, normal, or high. The "abnormal" mineralization may include defective or precipitous diffuse mineralization as in woven osteoid [72]. This classification should help the clinicians to focus on correcting the bone abnormalities observed in their patients and direct appropriate therapies.

In patients with CKD stages $2-5$ before dialysis, various abnormalities have been described ranging from mild increase in bone turnover resulting from moderate SHPT, with or without mineralization defect [73-75], to various degrees of LTBD [76]. In an ongoing study, we found that the majority of adult patients with CKD stages $2-5$ predialysis have low or low-normal bone turnover without mineralization defect. When patients reach ESRD, the bone abnormalities usually intensify. The spectrum of ROD histological features is very wide and has evolved over time. Traditionally, the various forms of ROD encompass predominant SHPT, adynamic bone disease, low turnover osteomalacia, and mixed uremic osteodystrophy. Predominant SHPT bone disease is characterized by HTBD with increased formation and resorption surfaces. Osteoid volume and surface are high with numer-

Assessment of Bone Quality in CKD

Patients ous irregular osteoblasts and osteocytes. In some areas, osteoid and mineralized bone lose their normal lamellar structure and become irregularly "woven." The resorption surfaces are high and resorption lacunae are deep with abundant multinucleated large osteoclasts. In addition, formation and resorption surfaces may be covered by peritrabecular fibrosis, which can extend deeply into the bone marrow. Under fluorescent light, the extent of tetracycline double labeling is high and may show diffuse uptake in woven osteoid. The cancellous bone volume/ tissue volume may be low, high, or normal, whereas cortical bone exhibits a high degree of porosity.

At the other end of the spectrum, patients may present with adynamic bone disease, where bone turnover is very low with paucity of bone formation sites and osteoblasts. Osteoid volume and surface are low with thin osteoid seams. Osteoid and bone are mostly lamellar but may show some remnants of woven structure from previous overactivity. Similarly, bone resorption surfaces may vary from low to slightly elevated. Under fluorescent microscopy, the mineralizing surfaces are mainly low with few thin passive single labels. Cancellous bone volume and cortical thickness are usually low.

Low-turnover osteomalacia in CKD patients is characterized by a severe mineralization defect with very high volume and surface of osteoid and wide osteoid seams. There is a paucity of osteoblasts. Resorption surfaces and osteoclasts may be seen on the few bone surfaces not covered with osteoid. The tetracycline uptake is minimal and consists of few thin single labels. This usually happens in patients with aluminum toxicity, where aluminum can be seen at the mineralization front. The cancellous bone volume and cortical thickness and porosity may vary from low to elevated.

Mixed ROD represents a combination of various degrees of SHPT along with signs of mineralization defect (osteomalacia). Bone volume and cortical thickness may vary.

The spectrum of bone diseases has evolved over the years [77]. In the early 1980s, there was a predominance of mixed ROD and low turnover osteomalacia (in the most severe cases) due to aluminum intoxication in ESRD patients. With prevention of aluminum toxicity in the subsequent years, the main histological forms of ROD consisted of various degrees of SHPT bone diseases. In the mid-1980s, the frequency of "aplastic" [78] or adynamic [79] bone disease increased significantly. Moreover, there are differences in the prevalence of the various histological forms of ROD between black and white patients with CKD. Black patients are less prone to develop LTBD and low bone volume [72, 73, 80-82]. 
In post-kidney transplant patients, several factors influence bone diseases such as pre-existing ROD, immunosuppressive therapy, and suboptimal kidney function. One of the prominent effects of renal transplantation is bone loss [83] with low bone volume/tissue volume and decrease in bone turnover [84-86]. Focal or generalized mineralization defects are also not uncommon [85].

Bone histomorphometry is mainly used for research $[87,88]$. The parameters that characterize bone turnover include bone formation rate/bone surface and activation frequency as well as number of osteoblasts and osteoclasts. Bone formation rate/bone surface relates exclusively to the level of bone formation, whereas activation frequency includes also parameters of bone resorption and quiescent periods and indicates the frequency at which the bone is completely renewed. Defective mineralization is defined as osteoid thickness $>20 \mu \mathrm{m}$ and mineralization lag lime $>100$ days. Volume encompasses cancellous bone volume/tissue volume, trabecular thickness, and separation as well as cortical thickness and porosity. Normal values vary by age, gender $[89,90]$, and race.

\section{FTIR Spectroscopy}

FTIR provides another way to measure bone quality on bone biopsy specimens. The chemical bonds between the components of bone matrix and mineralized bone, like all chemical bonds, undergo vibrations. The parameters of FTIR spectroscopy pertinent to bone material properties that are measured include (a) mineral to matrix ratio, (b) mineral maturity/degree of crystallization, (c) collagen cross-linking ratio (the relative proportion of mature to immature collagen), and (d) carbonate/phosphate ratio [91].

Malluche et al. [92] previously reported that mineral to matrix ratio is lower in dialysis patients with HTBD. This finding on FTIR in patients with HTBD correlated with lower hardness, as measured by nano-indentation techniques. There is shortened duration of remodeling cycle in HTBD, and this can lead to diminished duration of mineralization. This interferes with bone quality and leads to decreased bone stiffness [92]. In LTBD dialysis patients, there was no reduction in mineral to matrix ratio compared to normal controls. Hardness measured by nano-mechanical properties in this group was not decreased. However, the microstructural properties of bone, as measured by histomorphometry, such as trabecular volume and thickness were noted to be lower [92].
When combined with histological evaluation of the bone, FTIR can add valuable information on the bone material properties. As another example, changes in collagen cross-link ratio strongly suggest that factors other than bone turnover may be playing a role in the clinically manifested fragility. FTIR technique is not widely available, and it needs human tissue from a bone biopsy. FTIR can only measure relative quantities of minerals and matrix and the varying cross-link types and no absolute quantitation can be provided.

\section{Micro-Computed Tomography}

Micro-computed tomography is an ex vivo technique used to image small (millimeter-sized) bone samples using high amounts of radiation and can provide high-resolution 3D bone microstructural data [10]. It is not a clinically available technique but is considered the gold standard for measurement of bone structure against which other in vivo modalities are usually compared [57]. Sharma et al. [93] reported that micro-computed tomography was able to detect the deterioration of cortical microarchitecture in CKD patients. Of note, their cohort of patients did not have trabecular abnormalities.

\section{Conclusion}

CKD-induced bone quality and quantity abnormalities are complex disorders that confer high morbidity and mortality in the CKD population. Proper diagnosis of the actual underlying skeletal problems helps to prevent future bone loss and fractures. Once the diagnosis of ROD has been established, knowing the bone quality and turnover abnormality could help predict the fracture risk.

\section{Acknowledgements}

We thank the Kentucky Nephrology Research Trust for supporting our bone research. We also acknowledge the International Society of Nephrology for funding M.A. for his research fellowship.

\section{Statement of Ethics}

The authors have no ethical conflicts to disclose.

\section{Conflict of Interest Statement}

The authors have no conflicts of interest to disclose. 


\section{Funding Sources}

The authors received no specific funding for this article. No funding for the article design, preparation of the manuscript, or any other article-related work.

\section{Author Contributions}

All authors contributed equally in reviewing the literature and writing the manuscript.

\section{References}

1 Levin A, Stevens PE, Bilous RW, Coresh J, De Francisco AL, De Jong PE, et al. KDIGO 2012 clinical practice guideline for the evaluation and management of chronic kidney disease. Kidney Int Suppl. 2013;3(1):1-150.

2 Moe S, Drüeke T, Cunningham J, Goodman W, Martin K, Olgaard K, et al. Definition, evaluation, and classification of renal osteodystrophy: a position statement from Kidney Disease: Improving Global Outcomes (KDIGO). Kidney Int. 2006;69(11):1945-53.

3 WHO. Assessment of fracture risk and its application to screening for postmenopausal osteoporosis: report of a WHO study group [meeting held in Rome from 22 to 25 June 1992]. World Health Organization; 1994.

4 Donovan MA, Dempster D, Zhou H, McMahon DJ, Fleischer J, Shane E. Low bone formation in premenopausal women with idiopathic osteoporosis. J Clin Endocrinol Metab. 2005;90(6):3331-6.

5 Kulak M, Moreira CA, Schussheim M, Debra $\mathrm{H}$, McMahon MDJ, Kurland M, et al. Osteoporosis and low bone mass in premenopausal and perimenopausal women. Endocr Pract. 2000;6(4):296-304.

6 Khosla S, Lufkin EG, Hodgson SF, Fitzpatrick LA, Melton LJ III. Epidemiology and clinical features of osteoporosis in young individuals. Bone. 1994;15(5):551-5.

7 NIH Consensus Development Panel. Osteoporosis prevention, diagnosis, and therapy. JAMA. 2001;285(6):785-95.

8 Sprague SM, Bellorin-Font E, Jorgetti V, Carvalho $A B$, Malluche $H H$, Ferreira A, et al. Diagnostic accuracy of bone turnover markers and bone histology in patients with CKD treated by dialysis. Am J Kidney Dis. 2016; 67(4):559-66.

9 Kanis JA, Johnell O, Odén A, Johansson $\mathrm{H}$, McCloskey E. FRAX and the assessment of fracture probability in men and women from the UK. Osteoporos Int. 2008;19(4):385-97.

10 Malluche HH, Porter DS, Pienkowski D. Evaluating bone quality in patients with chronic kidney disease. Nat Rev Nephrol. 2013;9(11):671.

11 Delmas PD, Confavreux E, Garnero P, Fardellone P, de Vernejoul MC, Cormier C, et al. A combination of low doses of 17 beta-estradiol and norethisterone acetate prevents bone loss and normalizes bone turnover in postmenopausal women. Osteoporos Int. 2000;11(2): $177-87$.
12 Sprague SM, Bellorin-Font E, Jorgetti V, Carvalho $\mathrm{AB}$, Malluche $\mathrm{HH}$, Ferreira A, et al. Diagnostic accuracy of bone turnover markers and bone histology in patients with CKD treated by dialysis. Am J Kidney Dis. 2016; 67(4):559-66.

13 Monier-Faugere MC, Geng Z, Mawad H, Friedler RM, Gao P, Cantor TL, et al. Improved assessment of bone turnover by the PTH-(1-84)/large C-PTH fragments ratio in ESRD patients. Kidney Int. 2001;60(4):14608

14 Ureña P, Hruby M, Ferreira A, Ang KS, de Vernejoul MC. Plasma total versus bone alkaline phosphatase as markers of bone turnover in hemodialysis patients. J Am Soc Nephrol. 1996;7(3):506-12.

15 Nickolas TL, Cremers S, Zhang A, Thomas V, Stein E, Cohen A, et al. Discriminants of prevalent fractures in chronic kidney disease. J Am Soc Nephrol. 2011;22(8):1560-72.

16 Nickolas TL, Stein EM, Dworakowski E, Nishiyama KK, Komandah-Kosseh M, Zhang $\mathrm{CA}$, et al. Rapid cortical bone loss in patients with chronic kidney disease. J Bone Miner Res. 2013;28(8):1811-20.

17 Laowalert S, Khotavivattana T, Wattanachanya L, Luangjarmekorn P, Udomkarnjananun S, Katavetin P, et al. Bone turnover markers predict type of bone histomorphometry and bone mineral density in Asian chronic haemodialysis patients. Nephrology. 2020; 25(2):163-71.

18 Limori S, Mori Y, Akita W, Kuyama T, Takada S, Asai T, et al. Diagnostic usefulness of bone mineral density and biochemical markers of bone turnover in predicting fracture in CKD stage $5 \mathrm{D}$ patients: a single-center cohort study. Nephrol Dial Transplant. 2012;27(1): 345-51.

19 Perrin P, Caillard S, Javier RM, Braun L, Heibel F, Borni-Duval C, et al. Persistent hyperparathyroidism is a major risk factor for fractures in the five years after kidney transplantation. Am J Transplant. 2013;13(10): 2653-63.

20 Lima F, El-Husseini A, Monier-Faugere MC, David V, Mawad H, Quarles D, et al. FGF-23 serum levels and bone histomorphometric results in adult patients with chronic kidney disease on dialysis. Clin Nephrol. 2014;82(5): 287-95.

21 Terpos E, Christoulas D, Gavriatopoulou M, Dimopoulos MA. Mechanisms of bone destruction in multiple myeloma. Eur J Cancer Care. 2017;26(6).
22 Lima F, Mawad H, El-Husseini AA, Davenport DL, Malluche HH. Serum bone markers in ROD patients across the spectrum of decreases in GFR: activin A increases before all other markers. Clin Nephrol. 2019;91(4): 222-30.

23 Pelletier S, Dubourg L, Carlier MC, Hadj-Aissa $\mathrm{A}$, Fouque D. The relation between renal function and serum sclerostin in adult patients with CKD. Clin J Am Soc Nephrol. 2013;8(5):819-23.

24 Kanbay M, Siriopol D, Saglam M, Kurt YG, Gok M, Cetinkaya H, et al. Serum sclerostin and adverse outcomes in nondialyzed chronic kidney disease patients. J Clin Endocrinol Metab. 2014;99(10):E1854-61.

25 Asadipooya K, Weinstock A. Cardiovascular outcomes of romosozumab and protective role of alendronate. Arterioscler Thromb Vasc Biol. 2019;39(7):1343-50.

26 Mare A, Verhulst A, Cavalier E, Delanaye P, Behets GJ, Meijers B, et al. Clinical inference of serum and bone sclerostin levels in patients with end-stage kidney disease. J Clin Med. 2019;8(12):2027.

27 Cejka D, Herberth J, Branscum AJ, Fardo DW, Monier-Faugere MC, Diarra D, et al. Sclerostin and Dickkopf-1 in renal osteodystrophy. Clin J Am Soc Nephrol. 2011;6(4): $877-82$

28 Malluche $\mathrm{HH}$, Davenport DL, Cantor T, Monier-Faugere MC. Bone mineral density and serum biochemical predictors of bone loss in patients with CKD on dialysis. Clin J Am Soc Nephrol. 2014;9(7):1254-62.

29 Bielesz BO, Hempfing T, Kieweg H, Marculescu R, Haas M, Cejka D. Sclerostin declines during hemodialysis and appears in dialysate. Blood Purif. 2014;38(1):30-6.

30 Yamada S, Tsuruya K, Tokumoto M, Yoshida H, Ooboshi H, Kitazono T. Factors associated with serum soluble inhibitors of Wnt-betacatenin signaling (sclerostin and dickkopf-1) in patients undergoing peritoneal dialysis. Nephrology. 2015;20(9):639-45.

31 Harris WH, Heaney RP. Skeletal renewal and metabolic bone disease. N Engl J Med. 1969; 280(4):193-202 contd.

32 Jergas M, Uffmann M, Escher $H$, Schaffstein J, Nitzschke E, Köster O. [Visual evaluation of conventional roentgen pictures and dual $\mathrm{x}$ ray absorptiometry in the diagnosis of osteopenia]. Z Orthop Ihre Grenzgeb. 1994;132(2): 91-8. 
33 Adragao T, Herberth J, Monier-Faugere MC, Branscum AJ, Ferreira A, Frazao JM, et al. Low bone volume: a risk factor for coronary calcifications in hemodialysis patients. Clin J Am Soc Nephrol. 2009;4(2):450-5.

34 Tseng T-H, Mu C-F, Hsu C-Y. The correlation between renal function and bone mineral density. Minerva Urol Nefrol. 2014;66(3): 153-6.

35 Schacter GI, Leslie WD, Majumdar SR, Morin SN, Lix LM, Hans D. Clinical performance of an updated trabecular bone score (TBS) algorithm in men and women: the Manitoba BMD cohort. Osteoporos Int. 2017;28(11): 3199-203.

36 Leslie WD, Krieg MA, Hans D, Manitoba Bone Density P. Clinical factors associated with trabecular bone score. J Clin Densitom. 2013;16(3):374-9.

37 Paggiosi MA, Peel NF, Eastell R. The impact of glucocorticoid therapy on trabecular bone score in older women. Osteoporos Int. 2015; 26(6):1773-80.

38 Bonaccorsi G, Cafarelli FP, Cervellati C, De Guio F, Greco P, Giganti M, et al. A new corrective model to evaluate TBS in obese postmenopausal women: a cross-sectional study. Aging Clin Exp Res. 2020 Jul;32(7):1303-8.

39 Dusceac R, Niculescu DA, Dobre R, Dragne MC, Tacu C, Peride I, et al. Chronic hemodialysis is associated with lower trabecular bone score, independent of bone mineral density: a case-control study. Arch Osteoporos. 2018; 13(1): 125 .

40 Silva BC, Leslie WD, Resch H, Lamy O, Lesnyak $\mathrm{O}$, Binkley $\mathrm{N}$, et al. Trabecular bone score: a noninvasive analytical method based upon the DXA image. J Bone Miner Res. 2014; 29(3):518-30.

41 Shevroja E, Lamy O, Hans D. Review on the utility of trabecular bone score, a surrogate of bone micro-architecture, in the chronic kidney disease spectrum and in kidney transplant recipients. Front Endocrinol. 2018;9: 561.

42 Ramalho J, Marques IDB, Hans D, Dempster $\mathrm{D}$, Zhou H, Patel P, et al. The trabecular bone score: relationships with trabecular and cortical microarchitecture measured by $\mathrm{HR}$ pQCT and histomorphometry in patients with chronic kidney disease. Bone. 2018;116: 215-20.

43 Holloway-Kew KL, Rufus-Membere P, Anderson KB, Betson A, Gaston J, Kotowicz MA, et al. Bone material strength index is associated with prior fracture in men with and without moderate chronic kidney disease. Bone. 2020;133:115241.

44 Perez-Saez MJ, Herrera S, Prieto-Alhambra D, Nogues X, Vera M, Redondo-Pachon D, et al. Bone density, microarchitecture, and tissue quality long-term after kidney transplant. Transplantation. 2017;101(6):1290-4.

45 Guglielmi G, Scalzo G, de Terlizzi F, Peh WC. Quantitative ultrasound in osteoporosis and bone metabolism pathologies. Radiol Clin North Am. 2010;48(3):577-88.
46 Guglielmi G, Adams J, Link TM. Quantitative ultrasound in the assessment of skeletal status. Eur Radiol. 2009;19(8):1837-48.

47 Foldes AJ, Arnon E, Popovtzer MM. Reduced speed of sound in tibial bone of haemodialysed patients: association with serum PTH level. Nephrol Dial Transplant. 1996;11(7): 1318-21.

48 Żywiec J, Pluskiewicz W, Adamczyk P, Skubala A, Gumprecht J. Phalangeal quantitative ultrasound measurements in chronic hemodialysis patients: a 4-year follow-up. Ultrasound Med Biol. 2012 Jun;38(6):962-71.

49 Arici M, Erturk H, Altun B, Usalan C, Ulusoy $\mathrm{S}$, Erdem $\mathrm{Y}$, et al. Bone mineral density in haemodialysis patients: a comparative study of dual冈energy X®ray absorptiometry and quantitative ultrasound. Nephrol Dial Transplant. 2000;15(11):1847-51.

50 Przedlacki J, Pluskiewicz W, Wieliczko M, Drozdzowska B, Matuszkiewicz-Rowińska J, Bogdańska-Straszyńska B, et al. Quantitative ultrasound of phalanges and dual-energy $\mathrm{X}$ ray absorptiometry of forearm and hand in patients with end-stage renal failure treated with dialysis. Osteoporos Int. 1999;10(1):1-6.

51 Peretz A, Penaloza A, Mesquita M, Dratwa M, Verhas M, Martin P, et al. Quantitative ultrasound and dual X-ray absorptiometry measurements of the calcaneus in patients on maintenance hemodialysis. Bone. 2000;27(2): 287-92.

52 Kanis JA, Johnell O, Odén A, De Laet C, De Terlizzi F. Ten-year probabilities of clinical vertebral fractures according to phalangeal quantitative ultrasonography. Osteoporos Int. 2005;16(9): 1065-70.

53 Nickolas TL, Stein E, Cohen A, Thomas V, Staron RB, McMahon DJ, et al. Bone mass and microarchitecture in CKD patients with fracture. J Am Soc Nephrol. 2010;21(8):1371-80.

54 Pimentel A, Ureña-Torres P, Zillikens MC Bover J, Cohen-Solal M. Fractures in patients with CKD: diagnosis, treatment, and prevention: a review by members of the European Calcified Tissue Society and the European Renal Association of Nephrology Dialysis and Transplantation. Kidney Int. 2017;92(6): 1343-55.

55 Liu XS, Zhang XH, Sekhon KK, Adams MF, McMahon DJ, Bilezikian JP, et al. High-resolution peripheral quantitative computed tomography can assess microstructural and mechanical properties of human distal tibial bone. J Bone Miner Res. 2010;25(4):746-56.

56 Sharma AK, Toussaint ND. Is there a practical role for a virtual bone biopsy using high-resolution imaging of bone in patients with chronic kidney disease? Nephrology. 2017; 22(Suppl 2):27-30.

57 Sharma AK, Toussaint ND, Elder GJ, Masterson R, Holt SG, Robertson PL, et al. Magnetic resonance imaging based assessment of bone microstructure as a non-invasive alternative to histomorphometry in patients with chronic kidney disease. Bone. 2018;114:1421.
58 Boutroy S, Van Rietbergen B, Sornay-Rendu E, Munoz F, Bouxsein ML, Delmas PD. Finite element analysis based on in vivo HR-pQCT images of the distal radius is associated with wrist fracture in postmenopausal women. J Bone Miner Res. 2008;23(3):392-9.

59 Rajapakse CS, Leonard MB, Bhagat YA, Sun W, Magland JF, Wehrli FW. Micro-MR imaging-based computational biomechanics demonstrates reduction in cortical and trabecular bone strength after renal transplantation. Radiology. 2012;262(3):912-20.

60 Johannesdottir F, Allaire B, Bouxsein ML Fracture prediction by computed tomography and finite element analysis: current and future perspectives. Curr Osteoporos Rep. 2018;16(4):411-22.

61 Rajapakse CS, Chang G. Micro-finite element analysis of the proximal femur on the basis of high-resolution magnetic resonance images. Curr Osteoporos Rep. 2018;16(6):657-64.

62 Trombetti A, Stoermann C, Chevalley T, Van Rietbergen B, Herrmann FR, Martin PY, et al. Alterations of bone microstructure and strength in end-stage renal failure. Osteoporos Int. 2013;24(5):1721-32.

63 Diez-Perez A, Güerri R, Nogues X, Cáceres E, Peña MJ, Mellibovsky L, et al. Microindentation for in vivo measurement of bone tissue mechanical properties in humans. J Bone Miner Res. 2010;25(8):1877-85

64 Bridges D, Randall C, Hansma PK. A new device for performing reference point indentation without a reference probe. Rev Sci Instrum. 2012;83(4):044301.

65 Randall C, Bridges D, Guerri R, Nogues X, Puig L, Torres E, et al. Applications of a new handheld reference point indentation instrument measuring bone material strength. J Med Device. 2013;7(4):410051.

66 Güerri-Fernández RC, Nogués X, Quesada Gómez JM, Torres del Pliego E, Puig L, García-Giralt N, et al. Microindentation for in vivo measurement of bone tissue material properties in atypical femoral fracture patients and controls. J Bone Miner Res. 2013; 28(1):162-8.

67 Malluche HH, Faugere MC. Atlas of mineralized bone histology. New York: Karger; 1986.

68 Manaka RC, Malluche HH. A program package for quantitative analysis of histologic structure and remodeling dynamics of bone. Comput Programs Biomed. 1981;13(3-4): 191-201.

69 Malluche HH, Porter DS, Monier-Faugere MC, Mawad H, Pienkowski D. Differences in bone quality in low- and high-turnover renal osteodystrophy. J Am Soc Nephrol. 2012; 23(3):525-32.

70 Malluche HH, Porter DS, Pienkowski D. Evaluating bone quality in patients with chronic kidney disease. Nat Rev Nephrol. 2013;9(11):671-80. 
71 Moe S, Drüeke T, Cunningham J, Goodman W, Martin K, Olgaard K, et al. Definition, evaluation, and classification of renal osteodystrophy: a position statement from Kidney Disease: Improving Global Outcomes (KDIGO). Kidney Int. 2006;69(11):1945-53.

72 Malluche HH, Monier-Faugere MC. Renal osteodystrophy: what's in a name? Presentation of a clinically useful new model to interpret bone histologic findings. Clin Nephrol. 2006;65(4):235-42.

73 Laster M, Pereira RC, Salusky IB. Racial differences in bone histomorphometry in children and young adults treated with dialysis. Bone. 2019;127:114-9.

74 Malluche H, Faugere MC. Renal bone disease 1990: an unmet challenge for the nephrologist. Kidney Int. 1990;38(2):193-211.

75 Wesseling-Perry K, Salusky IB. Chronic kidney disease: mineral and bone disorder in children. Semin Nephrol. 2013;33(2):169-79.

76 Baker LR, Abrams L, Roe CJ, Faugere MC, Fanti P, Subayti Y, et al. 1,25(OH)2D3 administration in moderate renal failure: a prospective double-blind trial. Kidney Int. 1989; 35(2):661-9.

77 Malluche HH, Mawad HW, Monier-Faugere MC. Renal osteodystrophy in the first decade of the new millennium: analysis of 630 bone biopsies in black and white patients. J Bone Miner Res. 2011;26(6):1368-76.

78 Hercz G, Pei Y, Greenwood C, Manuel A, Saiphoo C, Goodman WG, et al. Aplastic osteodystrophy without aluminum: the role of "suppressed" parathyroid function. Kidney Int. 1993;44(4):860-6.

79 Malluche HH, Monier-Faugere MC. Risk of adynamic bone disease in dialyzed patients. Kidney Int Suppl. 1992;38:S62-7.
80 Fehmi H, Osman Y, Bhat S, Nguyen K, Daramola $\mathrm{O}$, Cantor T, et al. Absence of adynamic bone disease in African-Americans with CKD stage 5 after 3 years of vitamin D therapy guided by iPTH and the PTH-(1-84)/N-terminally truncated PTH fragments ratio. Clin Nephrol. 2009;71(3): $267-75$.

81 Herberth J, Branscum AJ, Mawad H, Cantor $\mathrm{T}$, Monier-Faugere MC, Malluche HH. Intact PTH combined with the PTH ratio for diagnosis of bone turnover in dialysis patients: a diagnostic test study. Am J Kidney Dis. 2010; 55(5):897-906.

82 Sawaya BP, Butros R, Naqvi S, Geng Z, Mawad $\mathrm{H}$, Friedler R, et al. Differences in bone turnover and intact PTH levels between African American and Caucasian patients with endstage renal disease. Kidney Int. 2003;64(2): 737-42.

83 Julian BA, Laskow DA, Dubovsky J, Dubovsky EV, Curtis JJ, Quarles LD. Rapid loss of vertebral mineral density after renal transplantation. N Engl J Med. 1991;325(8):544-50.

84 Malluche HH, Monier-Faugere MC, Herberth J. Bone disease after renal transplantation. Nat Rev Nephrol. 2010;6(1):32-40.

85 Monier-Faugere MC, Mawad H, Qi Q, Friedler RM, Malluche HH. High prevalence of low bone turnover and occurrence of osteomalacia after kidney transplantation. J Am Soc Nephrol. 2000;11(6):1093-9.

86 Sanchez CP, Salusky IB, Kuizon BD, Ramirez JA, Gales B, Ettenger RB, et al. Bone disease in children and adolescents undergoing successful renal transplantation. Kidney Int. 1998; 53(5):1358-64.
87 Dempster DW, Compston JE, Drezner MK, Glorieux FH, Kanis JA, Malluche H, et al. Standardized nomenclature, symbols, and units for bone histomorphometry: a 2012 update of the report of the ASBMR Histomorphometry Nomenclature Committee. J Bone Miner Res. 2013;28(1):2-17.

88 Parfitt AM, Drezner MK, Glorieux FH, Kanis JA, Malluche H, Meunier PJ, et al. Bone histomorphometry: standardization of nomenclature, symbols, and units. Report of the ASBMR Histomorphometry Nomenclature Committee. J Bone Miner Res. 1987;2(6): 595-610.

89 Malluche HH, Meyer W, Sherman D, Massry SG. Quantitative bone histology in 84 normal American subjects. Micromorphometric analysis and evaluation of variance in iliac bone. Calcif Tissue Int. 1982;34(5):449-55.

90 Glorieux FH, Travers R, Taylor A, Bowen JR, Rauch F, Norman M, et al. Normative data for iliac bone histomorphometry in growing children. Bone. 2000;26(2):103-9.

91 Paschalis EP, Mendelsohn R, Boskey AL. Infrared assessment of bone quality: a review. Clin Orthop Relat Res. 2011;469(8):2170-8.

92 Malluche $\mathrm{HH}$, Porter DS, Monier-Faugere MC, Mawad H, Pienkowski D. Differences in bone quality in low- and high-turnover renal osteodystrophy. J Am Soc Nephrol. 2012; 23(3):525-32.

93 Sharma AK, Toussaint ND, Masterson R, Holt SG, Rajapakse CS, Ebeling PR, et al. Deterioration of cortical bone microarchitecture: critical component of renal osteodystrophy evaluation. Am J Nephrol. 2018;47(6): 376-84. 